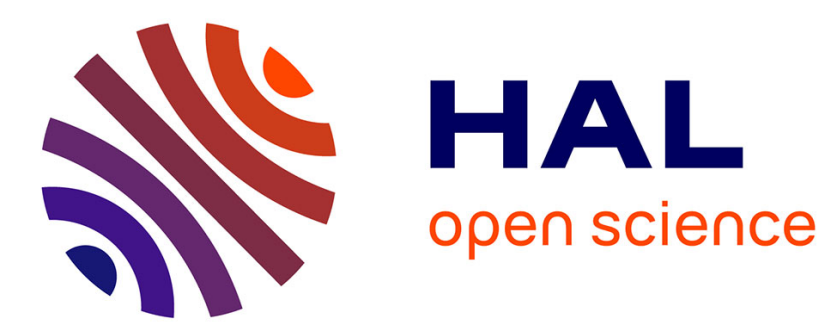

\title{
Structure and Activity of the Type VI Secretion System
}

Yassine Cherrak, Nicolas Flaugnatti, Eric Durand, Laure Journet, E. Cascales

\section{To cite this version:}

Yassine Cherrak, Nicolas Flaugnatti, Eric Durand, Laure Journet, E. Cascales. Structure and Activity of the Type VI Secretion System. Microbiology Spectrum, 2019, 7 (4), 10.1128/microbiolspec.PSIB0031-2019 . hal-02341386

\section{HAL Id: hal-02341386 \\ https://hal-amu.archives-ouvertes.fr/hal-02341386}

Submitted on 31 Oct 2019

HAL is a multi-disciplinary open access archive for the deposit and dissemination of scientific research documents, whether they are published or not. The documents may come from teaching and research institutions in France or abroad, or from public or private research centers.
L'archive ouverte pluridisciplinaire HAL, est destinée au dépôt et à la diffusion de documents scientifiques de niveau recherche, publiés ou non, émanant des établissements d'enseignement et de recherche français ou étrangers, des laboratoires publics ou privés. 
2

3 Yassine Cherrak $^{1}$, Nicolas Flaugnatti ${ }^{1,2}$, Eric Durand, Laure Journet, \& Eric Cascales

4

5 Laboratoire d'Ingénierie des Systèmes Macromoléculaires (LISM), Institut de Microbiologie 6 de la Méditerranée (IMM), Aix-Marseille Université - CNRS, UMR 7255, 31 chemin Joseph 7 Aiguier, 13402 Marseille Cedex 20, France

8

$9 \quad{ }^{1}$ These authors contributed equally to this review

$10{ }^{2}$ Current address: Laboratory of Molecular Microbiology, Global Health Institute, School of 11 Life Sciences, Ecole Polytechnique Fédérale de Lausanne (EPFL), Lausanne, Switzerland. 


\section{ABSTRACT}

13 The Type VI secretion system (T6SS) is a multiprotein machine that uses a spring-like

14 mechanism to inject effectors into target cells. The injection apparatus is composed of a 15 baseplate on which is built a contractile tail tube/sheath complex. The inner tube, topped by 16 the spike complex, is propelled outside of the cell by the contraction of the sheath. The 17 injection system is anchored to the cell envelope and oriented towards the cell exterior by a 18 trans-envelope complex. Effectors delivered by the T6SS are loaded within the inner tube or 19 on the spike complex, and can target prokaryotic and/or eukaryotic cells. Here, we summarize 20 the structure, assembly and mechanism of action of the T6SS. We also review the function of 21 effectors and their mode of recruitment and delivery. 


\section{INTRODUCTION}

24 The Type VI secretion system (T6SS) is a multiprotein machine that belongs to the versatile 25 family of contractile injection systems (CISs) (1-4). CISs deliver effectors into target cells 26 using a spring-like mechanism (4-6). Briefly, CISs assemble a needle-like structure, loaded

27 with effectors, wrapped into a sheath built in an extended, metastable, conformation (Fig. 1).

28 Contraction of the sheath propels the needle toward the competitor cell. Genomes of Gramnegative bacteria usually encode one or several T6SSs, with an overrepresentation in Proteobacteria and Bacteroidetes (for a review on the role of T6SS in gut-associated Bacteroidales, see chapter by Coyne and Comstock (7)) (8-10). The broad arsenal of effectors delivered by T6SS includes antibacterial-specific proteins such as peptidoglycan hydrolases, eukaryotic-specific effectors that act on cell cytoskeleton, and toxins that can target all cell types such as DNases, phospholipases, or NAD ${ }^{+}$hydrolases (11-14). As such, the T6SS plays a critical role in reshaping bacterial communities, and directly, or indirectly, in pathogenesis (15-19). Destroying bacterial competitors also provides exogenous DNA that can be acquired in naturally competent bacteria and that serves as reservoir for antibiotic resistance gene spreading (20). This chapter lists the major effector families, and summarizes the current knowledge on the assembly and mode of action of the T6SS.

\section{TYPE VI SECRETION SYSTEM EFFECTORS}

Several T6SSs have been shown to target eukaryotic cells (21-23). By promoting or preventing cytoskeleton re-arrangements through the action of specific effectors that target actin or tubulin, the T6SSs of Vibrio cholerae, Aeromonas hydrophila, and Pseudomonas aeruginosa disable phagocytic cells or stimulate internalization into non-phagocytic cells (21, 22, 24-26). Other T6SSs have been demonstrated to manipulate host cells, although the molecular determinants are not yet entirely understood (27-30). However, T6SS gene clusters 
are widespread in Gram-negative bacterial genomes, and not restricted to pathogens (10).

Most of them encode proteins with potent antibacterial activities such as enzymes that cleave essential macromolecules such as DNA, phospholipids or the peptidoglycan mesh, or essential metabolites such as $\mathrm{NAD}^{+} / \mathrm{NADP}^{+}$(31-36). Additional T6SS antibacterial effectors

52 include ADP-ribosyltransferases that specifically target the Z-ring and hence inhibit cell

53 division (37). Antibacterial effectors are active in the periplasm or cytoplasm of the target cell, and are co-produced with immunity proteins that remain in the producing cell and act as antitoxins to prevent autointoxication during dueling between sister cells (11-13). More recently, T6SS effectors that collect manganese or zinc in the environment to provide metals to the cell have been described (38-40). By deploying antibacterial effectors or scavenging metals, T6SSs play an important role in bacterial communities, and hence T6SS gene clusters are usually highly represented in species present in multispecies microbiota such as the human gut $(7,16-18,41)$. In general the regulatory mechanisms and signals underlying expression of T6SS genes, production of T6SS subunits or post-translational activation of the secretion apparatus are tightly linked to environmental cues in the niche in which the T6SS is required destroy competitors (42-45).

\section{TYPE VI SECRETION MECHANISM OF ACTION}

T6SSs use a contractile mechanism to inject effectors (Fig. 2). This mechanism is shared with all CISs: a sheath, assembled in an extended conformation, wraps a needle. Contraction of the sheath into a stable state propels the needle $(1,3-5)$. The needle is composed of an inner tube capped by the spike complex that pierces the membrane of the target cell (Fig. 1). The tail tube/sheath complex (TTC) is built on an assembly platform named baseplate (BP) (Fig. 1).

71 TTC and BP are collectively called tail, a structure that is conserved among all CISs. In

72 addition to this common theme to all CISs, T6SSs have evolved (i) a membrane complex 
73 (MC), which docks the tail to the cell envelope and serves as channel for the passage of the 74 needle upon sheath contraction, and (ii) a specialized BP component to properly orient the needle toward the cell exterior, by recognizing and binding the MC (2-5, 46-48) (Fig. 1). T6SS biogenesis starts with the assembly of the MC in the cell envelope, and that of

77 the BP in the cytoplasm (49-51) (Fig. 2). Once the BP is docked to the MC, the inner tube and 78 sheath are coordinately assembled (49-52) (Fig. 2).

\section{ARCHITECTURE OF THE TYPE VI SECRETION SYSTEM}

\section{The Membrane Complex}

The vast majority of T6SS gene clusters of Proteobacterial species encode three membrane proteins: TssJ, TssL, and TssM $(8-10,53)$ (Fig. 1). TssJ is an outer membrane-associated lipoprotein that protrudes in the periplasm (54). TssL and TssM are anchored in the inner membrane (55-57). The structures of several TssJ homologues have been reported: they all share a classical transthyretin fold with an additional loop, of variable length and composition, located between $\beta$-strands 1 and 2 (58-60). TssL bears a single C-terminal membrane-spanning segment (56) and a cytoplasmic domain that comprises two bundles of $\alpha$-helices (61-63). TssM possesses three transmembrane helices followed by a large periplasmic region $(55,57)$. The periplasmic region of TssM comprises three domains, including the C-terminal domain that engages in interaction with the TssJ extra-loop $(49,58)$, TssL and TssM interact through their transmembrane segments $(55,64,65)$. The cytoplasmic domains of TssL and TssM mediate contacts with the baseplate $(50,57,64,66,67)$.

The electron microscopy structure of the fully assembled 1.7-MDa TssJLM MC from enteroaggregative Escherichia coli has been reported $(49,68,69)$. The complex has a rocketlike structure: a large base, that contains the cytoplasmic and membrane domains of TssL and TssM, is followed by arches and pillars which correspond to the TssM periplasmic domains 
and TssJ (68). The TssJLM complex, which has five-fold symmetry in vivo and after purification, comprises 15 copies of TssJ, and 10 copies of TssL and of TssM $(49,58)$. The MC delimits an internal lumen with a diameter insufficient for the passage of the tail tube. In addition, this lumen is partly occluded by a periplasmic constriction gate, suggesting that 102 large conformational changes occur upon BP docking or sheath contraction $(49,58)$. proteins $(53,70,71)$. MC anchorage to the cell wall likely stabilizes the MC to resist the forces generated during sheath contraction (70). Finally, recent studies have shown that proper assembly of the MC requires the activity of peptidoglycan-degrading enzymes (72, 107 73).

Interestingly, while the tail complex is evolutionarily related to contractile injection machines, the evolution history of the MC is less clear. TssL and TssM present significant homologies with two accessory subunits associated with Type IVb secretion systems, DotU

111 and IcmF, respectively $(8,9)$. No homologue of TssJ is found associated with DotU/IcmF 112 complexes, suggesting that TssJ is from a different ancestry. Indeed, while essential when 113 present, TssJ is lacking in some T6SSs such as that of Agrobacterium and Acinetobacter. 114 Further studies are required to understand whether other proteins can substitute for the 115 absence of TssJ in these species. The fact that the MC has a distinct history compared to the 116 tail is also exemplified by the observation that no TssJLM complex is present in 117 Bacteroidales T6SSs $(74,75)$. However, putative uncharacterized membrane proteins are 118 encoded within these T6SS gene clusters suggesting that a different transenvelope complex 119 has been domesticated to anchor the tail $(74,75)$.

\section{The Tail}

\section{The baseplate}


123 The baseplate (BP) (Fig. 1) is a large complex of $2.7 \mathrm{MDa}$ comprising $>60$ polypeptides of at

124 least six different proteins (50). The role of the baseplate is to initiate the polymerization of

125 the tail tube/sheath complex. While it has not been formally shown yet, the T6SS baseplate is

126 believed to trigger sheath contraction, as demonstrated in other CISs. A specific role of the

127 T6SS baseplate is to anchor the TTC to the MC. The BP is composed of six wedge

128 subcomplexes organized around the central hub, i.e., the N-terminal domain of the VgrG

129 spike $(76,77)$ (Fig. 1). VgrG hence belongs to two tail sub-complexes: it constitutes the tip of

130 the needle, and the hub for the baseplate. The wedge complex is composed of 4 proteins:

131 TssE, $-\mathrm{F},-\mathrm{G}$, and $-\mathrm{K}$. These four proteins assemble a structure of 1:2:1:6 stoichiometry, the

132 TssG peptide being the central core (77-79). Two TssF subunits wrap TssG to form a

133 triangular shape called trifurcation unit, whereas two extensions of TssG make contacts with

134 two TssK trimers (77). TssE, $-\mathrm{F},-\mathrm{G}$ are respectively homologues of phage T4 gp25, gp6 and

135 gp7 and phage Mu Mup46, Mup47 and Mup48 (50, 77, 79, 80), that also constitute the inner

136 part of phage baseplates (79-81). TssK has no homologue in Myoviridae, but shares

137 architectural homologies with receptor-binding proteins (RBP) of Siphoviridae phages (67).

138 The structure of the N-terminal domain of TssK is superimposable with that of Siphoviridae

139 RBP shoulder domains that are anchored into the baseplate (67). Indeed, the TssK N-terminal

140 domain establishes extensive contacts with the $\mathrm{TssF}_{2} \mathrm{G}$ complex (67). The TssK C-terminal

141 domain has evolved to bind to the MC, and specifically to the TssL and TssM cytoplasmic

142 domains $(57,64,66,67)$. Similar to the MC, the BP can be accessorized by additional

143 subunits, such as TssA1 in $P$. aeruginosa (82), that may stabilize the complex or provide

144 additional functions.

145

146 The tail tube/sheath complex 
147 The tail tube/sheath complex comprises the needle and the contractile sheath (Fig. 1). It forms $148 \mathrm{a} \sim 1 \mu \mathrm{m}$-long tubular structure in the cytoplasm, that is assembled in $30-50 \mathrm{sec}(52,83)$.

150 is made of hexamers of the Hcp protein (84-86). These donut-shaped hexameric Hcp rings 151 (87, 88) stack on each other in a head-to-tail orientation to form a hollow tube (86).

152 Interestingly, despite very low sequence similarities between T6SS Hcps and tube proteins 153 from other CISs, their structure is strictly conserved (5). Hcp tube polymerization starts at the 154 baseplate, through direct recruitment of the first ring to the base of the VgrG hub/spike (89). 155 The spike complex is composed of a trimer of the VgrG protein and, in most instances, of the 156 PAAR-repeat protein $(85,90)$. VgrG contains several conserved domains $(24,85)$. The $\mathrm{N}$ 157 terminal domain resembles the phage $\mathrm{T} 4 \mathrm{gp} 27$ protein, and acts as a symmetry adaptor 158 between the six-fold symmetry of the inner tube and the three-fold symmetry of the VgrG central and C-terminal domains, which share homologies with the phage T4 gp5 N-terminal 160 and $\beta$-prism domains $(89,91,92)$. The $\operatorname{VgrG} \beta$-prism domain is a triangular $\beta$-helix that 161 forms, together with the conical PAAR protein, the penetration device of the T6SS needle $162(90,93)$. The VgrG trimer and the PAAR protein can be extended by additional domains that 163 may act as effectors, or as adaptors for effectors $(24,90)$.

164 The sheath polymerizes from the baseplate. It is proposed that, similarly to its gp25165 like homologues in Myoviridae, the TssE BP subunit constitutes the sheath polymerization 166 initiator $(79,91)$. By contrast to other CISs, the T6SS sheath is composed of two proteins, 167 TssB and TssC $(1,52,85,94,95)$, forming a stable dimer that is the repeat unit for sheath 168 polymerization (96-98). Six TssBC dimers form a strand that wraps a Hcp hexameric ring. 169 The TssBC dimer can be divided in three regions: Domains 1 and 2 that resemble CIS sheath 170 proteins, and an additional Domain 3 inserted into Domain 2 (99, 100). Extensive contacts 
171 between TssBC dimers from the same strand and from the neighboring -1 and +1 strands 172 stabilize the extended conformation of the sheath polymer $(100,101)$. In the T6SS, assembly of the inner tube and that of the extended sheath are 174 interdependent $(86,102)$. The TssA protein coordinates the polymerization of the tail 175 tube/sheath complex (103) (Fig. 2). TssA localizes at the distal extremity of the growing tail 176 tube/sheath (103), at the location in which hexameric tube rings and TssBC strands are 177 incorporated (104). TssA presents a 6-arm starfish-like structure with a central core (103).

178 Protein-protein interaction studies have suggested that the central core of TssA may undergo 179 large conformational changes to insert new Hcp hexamers, whereas the arms may facilitate 180 sheath polymerization $(103,105)$. Tail tube/sheath polymerization proceeds in the cytoplasm, 181 and is stopped when the distal end hits the membrane on the opposite membrane of the 182 bacterial cell $(104,106)$. A recent study has identified TagA, a protein that interacts with 183 TssA to stop the assembly of the tail and to maintain the sheath under the extended 184 conformation (106) (Fig. 2). However, the TssA cap protein and the TagA stopper are not 185 conserved in T6SS gene clusters, suggesting that different mechanisms control tail 186 tube/sheath assembly and termination in different $\mathrm{T} 6 \mathrm{SS}^{+}$species (105-107).

187 Contraction of the T6SS sheath, which occurs in less than 2-5 msec, is believed to start 188 at the BP. The cryo-electron microscopy structure of the Vibrio cholerae T6SS sheath has 189 been solved in the two states: extended and contracted, allowing a reconstitution of the 190 molecular events leading to contraction $(99,100)$. Contraction consists to a reorganization of 191 the TssBC strands, and notably an outward rotation of the sheath subunits (100). By doing so, 192 the sheath compacts on the $\mathrm{BP}$, and contacts with the inner tube are abolished, thus, 193 promoting its expulsion $(5,100,101)$. The free energy released during contraction is 194 estimated to $>44,000$ kcal.mol ${ }^{-1}$ for a $1-\mu \mathrm{m}$-long sheath (100). 
After contraction, the sheath is disassembled by a dedicated AAA $^{+}$ATPase, ClpV (94, 102) (Fig. 2). ClpV binds to an N-terminal helix of TssC that belongs to sheath Domain 3

$197(108,109)$, which is only accessible in the contracted conformation $(98,100)$. Although this is not clearly established, it is proposed that contracted sheath subunits are recycled rather than conveyed to degradation (102).

200

\section{LOADING AND TRANSPORT OF EFFECTORS}

As summarized above, a broad repertoire of anti-bacterial and anti-host activities have been already described for T6SS effectors. In addition, the mode of loading and transfer of these effectors into target cells is also variable. The common theme is that these effectors are associated with needle components, as the needle is the only portion of the T6SS to be propelled into the target cell $(12,13)$ (Fig. 3). Effectors can be additional domains fused to needle components such as Hcp, VgrG, or PAAR, or independent proteins that directly or indirectly bind to Hcp, VgrG, or PAAR $(12,13)$. Recruitment of these independent cargo effectors to Hcp, VgrG or PAAR can be mediated by adaptors, which are themselves domains of the needle components, or independent proteins (110) (Fig. 3).

\section{Specialized Hcp, VgrG and PAAR}

213 When the effector module is on the same polypeptide as the needle component, the T6SS

214 subunit is called "specialized" or "evolved". Although effectors fused to Hcp or PAAR have 215 been described $(36,90,111)$, the best-characterized examples are C-terminal extensions of 216 specialized VgrGs such as $V$. cholerae VgrG1 that cross-links actin and VgrG3 that has 217 peptidoglycan glycoside hydrolase activity, A. hydrophila VgrG1 that ADP-ribosylates actin, 218 P. aeruginosa VgrG2b that interacts with tubule cap complex, and Burkholderia pseudomallei 219 VgrG5 that induces host cell membrane fusion (21-26, 112-113). 


\section{Cargo Effectors}

222 Cargo effectors are independent proteins that need to recognize their Hcp, VgrG or PAAR 223 carrier for transfer. This recognition could be direct, such as the case of effectors that bind 224 Hcp, or may require an additional adaptor module that bind $\operatorname{VgrG}$ or PAAR $(12,13,110)$

225 (Fig. 3). Usually the effector genes are genetically linked to genes encoding their vehicle, 226 their adaptors (if any) and in case of antibacterial toxins, their immunity proteins. These 227 genetic elements could be found within T6SS gene clusters, or as Hcp-VgrG islands scattered 228 on the genome $(9,10)$.

When associated with Hcp, the effector is embedded in the lumen of the hexameric 230 ring, and is thus likely found inside the channel of the inner tube during T6SS assembly (16, 231 114). As such, it is protected and stabilized $(114,115)$. However the available space in the 232 Hcp ring lumen limits the size of the effector to be transported, which is estimated to be $<25$ $233 \mathrm{kDa}(114)$.

234 Adaptors can be isolated proteins, or domains fused to the cargo or the vehicle (110). 235 Adaptors from distinct families, such as DUF1795 (EagT6, EagR), DUF2169, DUF2345, 236 DUF4123 (Tap-1 or Tec), transthyretin (TTR) or Recombination hot-spot (Rhs) have been 237 described and studied $(35,90,116-125)$. When several copies of VgrG or PAAR proteins are 238 encoded within the genome, these adaptor modules specify the carriers on which the effector 239 should be mounted $(112,118,122,123,126)$. In addition to loading the effector on the 240 vehicle, some of these adaptors have been shown to act as chaperones to stabilize the effector, 241 or to wrap hydrophobic transmembrane segments to prevent effector aggregation $(112,124$, 242 125). 
245 Although the Type VI secretion system is one of the most recently identified secretion 246 apparati, we now have a detailed view on how the system is assembled, how it is structurally

247 arranged, and how effectors are loaded and transported. The broad repertoire of effectors has 248 only recently started to emerge, and it is likely that many effectors with interesting activities 249 will be identified and characterized in the next years. The discovery of the T6SS 13 years ago 250 and its role as an antibacterial weapon have altered our view of bacterial communities. It is 251 now broadly admitted that bacteria do not only cohabitate peacefully but rather that complex 252 interactions are established to maintain stable ecosystems, such as the human gut microbiota. 253 Further fundamental and translational works are required to better understand how T6SS 254 activation or inhibition may impact microbial communities and may perturb complex 255 ecosystems.

\section{ACKNOWLEDGMENTS}

We thank the laboratory members for helpful discussions and support. Our work on T6SS is supported by the Centre National de la Recherche Scientifique (CNRS), the Aix-Marseille 260 Université (AMU), and grants from the Agence Nationale de la Recherche (ANR-14-CE140006 and ANR-17-CE11-0039 to EC, ANR-18-CE15-0013 to LJ, ANR-18-CE11-0023 to ED), the Fondation pour la Recherche Médicale (DEQ20180339165), and the Fondation Bettencourt-Schueller. YC is supported by the FRM (FRM-ECO20160736014).

\section{REFERENCES}

1. Bönemann G, Pietrosiuk A, Mogk A. 2010. Tubules and donuts: a type VI secretion story. Mol Microbiol 76:815-821.

2. Zoued A, Brunet YR, Durand E, Aschtgen MS, Logger L, Douzi B, Journet L, Cambillau C, Cascales E. 2014. Architecture and assembly of the type VI secretion system. Biochim Biophys Acta 1843:1664-1673. 
3. Cascales E. 2017. Microbiology: and Amoebophilus invented the machine gun! Curr Biol 27:R1170-R1173.

4. Taylor NMI, van Raaij MJ, Leiman PG. 2018. Contractile injection systems of bacteriophages and related systems. Mol Microbiol 108:6-15.

5. Brackmann M, Nazarov S, Wang J, Basler M. 2017. Using force to punch holes: mechanics of contractile nanomachines. Trends Cell Biol 27:623-632.

6. Cianfanelli FR, Monlezun L, Coulthurst SJ. 2016. Aim, load, fire: the type VI secretion system, a bacterial nanoweapon. Trends Microbiol. 24:51-62. doi: 10.1016/j.tim.2015.10.005.

7. Coyne MJ, Comstock LE. 2019. Type VI secretion systems and the gut microbiota. Microbiol Spectr 7:2.

8. Bingle LE, Bailey CM, Pallen MJ. 2008. Type VI secretion: a beginner's guide. Curr Opin Microbiol 11:3-8.

9. Cascales E. 2008. The type VI secretion toolkit. EMBO Rep 9:735-741.

10. Boyer F, Fichant G, Berthod J, Vandenbrouck Y, Attree I. 2009. Dissecting the bacterial type VI secretion system by a genome wide in silico analysis: what can be learned from available microbial genomic resources? BMC Genomics 10:104.

11. Russell AB, Peterson SB, Mougous JD. 2014. Type VI secretion system effectors: poisons with a purpose. Nat Rev Microbiol 12:137-148.

12. Durand E, Cambillau C, Cascales E, Journet L. 2014. VgrG, Tae, Tle, and beyond: the versatile arsenal of type VI secretion effectors. Trends Microbiol 22:498-507.

13. Alcoforado Diniz J, Liu YC, Coulthurst SJ. 2015. Molecular weaponry: diverse effectors delivered by the Type VI secretion system. Cell Microbiol 17:1742-1751.

14. Hachani A, Wood TE, Filloux A. 2016. Type VI secretion and anti-host effectors. Curr Opin Microbiol 29:81-93.

15. Fu Y, Waldor MK, Mekalanos JJ. 2013. Tn-Seq analysis of Vibrio cholerae intestinal colonization reveals a role for T6SS-mediated antibacterial activity in the host. Cell Host Microbe. 14:652-63. doi: 10.1016/j.chom.2013.11.001.

16. Sana TG, Flaugnatti N, Lugo KA, Lam LH, Jacobson A, Baylot V, Durand E, Journet L, Cascales E, Monack DM. 2016. Salmonella Typhimurium utilizes a T6SS-mediated antibacterial weapon to establish in the host gut. Proc Natl Acad Sci USA. 113:E5044-51. doi: 10.1073/pnas.1608858113.

17. Sana TG, Lugo KA, Monack DM. 2017. T6SS: The bacterial "fight club" in the host gut. PLoS Pathog. 13:e1006325. doi: 10.1371/journal.ppat.1006325.

18. Chassaing B, Cascales E. 2018. Antibacterial weapons: targeted destruction in the microbiota. Trends Microbiol 26:329-338.

19. García-Bayona L, Comstock LE. 2018. Bacterial antagonism in host-associated microbial communities. Science. 361 pii: eaat2456. doi: 10.1126/science.aat 2456.

20. Veening JW, Blokesch M. 2017. Interbacterial predation as a strategy for DNA acquisition in naturally competent bacteria. Nat Rev Microbiol. 15:621-629. doi: 10.1038/nrmicro.2017.66.

21. Pukatzki S, Ma AT, Sturtevant D, Krastins B, Sarracino D, Nelson WC, Heidelberg JF, Mekalanos JJ. 2006. Identification of a conserved bacterial protein secretion system in Vibrio cholerae using the Dictyostelium host model system. Proc Natl Acad Sci USA. 103:1528-33.

22. Sana TG, Baumann C, Merdes A, Soscia C, Rattei T, Hachani A, Jones C, Bennett KL, Filloux A, Superti-Furga G, Voulhoux R, Bleves S. 2015. Internalization of Pseudomonas aeruginosa strain PAO1 into epithelial cells is promoted by interaction of a T6SS effector with the microtubule network. MBio. 6:e00712. doi: 10.1128/mBio.00712-15. 
23. Schwarz S, Singh P, Robertson JD, LeRoux M, Skerrett SJ, Goodlett DR, West TE, Mougous JD. 2014. VgrG-5 is a Burkholderia type VI secretion system-exported protein required for multinucleated giant cell formation and virulence. Infect Immun. 82:1445-52. doi: 10.1128/IAI.01368-13.

24. Pukatzki S, Ma AT, Revel AT, Sturtevant D, Mekalanos JJ. 2007. Type VI secretion system translocates a phage tail spike-like protein into target cells where it cross-links actin. Proc Natl Acad Sci USA. 104:15508-13.

25. Suarez G, Sierra JC, Erova TE, Sha J, Horneman AJ, Chopra AK. 2010. A type VI secretion system effector protein, VgrG1, from Aeromonas hydrophila that induces host cell toxicity by ADP ribosylation of actin. $J$ Bacteriol. 192:155-68. doi: 10.1128/JB.01260-09.

26. Durand E, Derrez E, Audoly G, Spinelli S, Ortiz-Lombardia M, Raoult D, Cascales E, Cambillau C. 2012. Crystal structure of the VgrG1 actin cross-linking domain of the Vibrio cholerae type VI secretion system. J Biol Chem. 287:38190-9. doi: 10.1074/jbc.M112.390153.

27. Aubert DF, Xu H, Yang J, Shi X, Gao W, Li L, Bisaro F, Chen S, Valvano MA, Shao F. 2016. A Burkholderia Type VI effector deamidates Rho GTPases to activate the pyrin inflammasome and trigger inflammation. Cell Host Microbe. 19:664-74. doi: 10.1016/j.chom.2016.04.004.

28. Eshraghi A, Kim J, Walls AC, Ledvina HE, Miller CN, Ramsey KM, Whitney JC, Radey MC, Peterson SB, Ruhland BR, Tran BQ, Goo YA, Goodlett DR, Dove SL, Celli J, Veesler D, Mougous JD. 2016. Secreted effectors encoded within and outside of the Francisella pathogenicity island promote intramacrophage growth. Cell Host Microbe. 20:573-583. doi: 10.1016/j.chom.2016.10.008.

29. Ledvina HE, Kelly KA, Eshraghi A, Plemel RL, Peterson SB, Lee B, Steele S, Adler M, Kawula TH, Merz AJ, Skerrett SJ, Celli J, Mougous JD. 2018. A phosphatidylinositol 3-kinase effector alters phagosomal maturation to promote intracellular growth of Francisella. Cell Host Microbe. 24:285-295.e8. doi: 10.1016/j.chom.2018.07.003.

30. Lennings J, West TE, Schwarz S. 2019. The Burkholderia Type VI secretion system 5: composition, regulation and role in virulence. Front Microbiol. 9:3339. doi: 10.3389/fmicb.2018.03339.

31. Hood RD, Singh P, Hsu F, Güvener T, Carl MA, Trinidad RR, Silverman JM, Ohlson BB, Hicks KG, Plemel RL, Li M, Schwarz S, Wang WY, Merz AJ, Goodlett DR, Mougous JD. 2010. A type VI secretion system of Pseudomonas aeruginosa targets a toxin to bacteria. Cell Host Microbe. 7:25-37. doi: 10.1016/j.chom.2009.12.007.

32. Russell AB, Hood RD, Bui NK, LeRoux M, Vollmer W, Mougous JD. 2011. Type VI secretion delivers bacteriolytic effectors to target cells. Nature. 75:343-7. doi: 10.1038/nature10244.

33. Russell AB, LeRoux M, Hathazi K, Agnello DM, Ishikawa T, Wiggins PA, Wai SN, Mougous JD. 2013. Diverse type VI secretion phospholipases are functionally plastic antibacterial effectors. Nature. 496:508-12. doi: 10.1038/nature12074.

34. Ma LS, Hachani A, Lin JS, Filloux A, Lai EM. 2014. Agrobacterium tumefaciens deploys a superfamily of type VI secretion DNase effectors as weapons for interbacterial competition in planta. Cell Host Microbe. 16:94-104. doi: 10.1016/j.chom.2014.06.002.

35. Whitney JC, Quentin D, Sawai S, LeRoux M, Harding BN, Ledvina HE, Tran BQ, Robinson H, Goo YA, Goodlett DR, Raunser S, Mougous JD. 2015. An 
interbacterial $\mathrm{NAD}(\mathrm{P})(+)$ glycohydrolase toxin requires elongation factor $\mathrm{Tu}$ for delivery to target cells. Cell. 163:607-19. doi: 10.1016/j.cell.2015.09.027.

36. Pissaridou P, Allsopp LP, Wettstadt S, Howard SA, Mavridou DAI, Filloux A. 2018. The Pseudomonas aeruginosa T6SS-VgrGlb spike is topped by a PAAR protein eliciting DNA damage to bacterial competitors. Proc Natl Acad Sci USA. 115:12519-12524. doi: 10.1073/pnas.1814181115.

37. Ting SY, Bosch DE, Mangiameli SM, Radey MC, Huang S, Park YJ, Kelly KA, Filip SK, Goo YA, Eng JK, Allaire M, Veesler D, Wiggins PA, Peterson SB, Mougous JD. 2018. Bifunctional immunity proteins protect bacteria against FtsZtargeting ADP-ribosylating toxins. Cell. 175:1380-1392 doi: 10.1016/j.cell.2018.09.037.

38. Wang T, Si M, Song Y, Zhu W, Gao F, Wang Y, Zhang L, Zhang W, Wei G, Luo ZQ, Shen X. 2015. Type VI secretion system transports Zn2+ to combat multiple stresses and host immunity. PLoS Pathog. 11:e1005020. doi: 10.1371/journal.ppat.1005020.

39. Si M, Zhao C, Burkinshaw B, Zhang B, Wei D, Wang Y, Dong TG, Shen X. 2017. Manganese scavenging and oxidative stress response mediated by type VI secretion system in Burkholderia thailandensis. Proc Natl Acad Sci USA. 114:E2233-E2242. doi: 10.1073/pnas.1614902114.

40. Si M, Wang Y, Zhang B, Zhao C, Kang Y, Bai H, Wei D, Zhu L, Zhang L, Dong TG, Shen X. 2017. The Type VI secretion system engages a redox-regulated dualfunctional heme transporter for zinc acquisition. Cell Rep. 20:949-959. doi: 10.1016/j.celrep.2017.06.081.

41. Verster AJ, Ross BD, Radey MC, Bao Y, Goodman AL, Mougous JD, Borenstein E. 2017. The landscape of type VI secretion across human gut microbiomes reveals Its role in community composition. Cell Host Microbe. 22:411-419 doi: 10.1016/j.chom.2017.08.010.

42. Bernard CS, Brunet YR, Gueguen E, Cascales E. 2010. Nooks and crannies in type VI secretion regulation. J Bacteriol. 192:3850-60. doi: 10.1128/JB.00370-10.

43. Silverman JM, Brunet YR, Cascales E, Mougous JD. 2012. Structure and regulation of the type VI secretion system. Annu Rev Microbiol. 66:453-72. doi: 10.1146/annurev-micro-121809-151619.

44. Miyata ST, Bachmann V, Pukatzki S. 2013. Type VI secretion system regulation as a consequence of evolutionary pressure. J Med Microbiol. 62:663-76. doi: 10.1099/jmm.0.053983-0.

45. LeRoux M, Peterson SB, Mougous JD. 2015. Bacterial danger sensing. J Mol Biol. 427:3744-53. doi: 10.1016/j.jmb.2015.09.018.

46. Ho BT, Dong TG, Mekalanos JJ. 2014. A view to a kill: the bacterial type VI secretion system. Cell Host Microbe 15:9-21.

47. Basler M. 2015. Type VI secretion system: secretion by a contractile nanomachine. Philos Trans R Soc Lond B Biol Sci 370:20150021.

48. Coulthurst S. 2019. The Type VI secretion system: a versatile bacterial weapon. Microbiology. doi: 10.1099/mic.0.000789.

49. Durand E, Nguyen VS, Zoued A, Logger L, Péhau-Arnaudet G, Aschtgen MS, Spinelli S, Desmyter A, Bardiaux B, Dujeancourt A, Roussel A, Cambillau C, Cascales E, Fronzes R. 2015. Biogenesis and structure of a type VI secretion membrane core complex. Nature 523:555-560.

50. Brunet YR, Zoued A, Boyer F, Douzi B, Cascales E. 2015. The type VI secretion TssEFGK-VgrG phage-like baseplate is recruited to the TssJLM membrane complex 
via multiple contacts and serves as assembly platform for tail tube/sheath polymerization. PLoS Genet 11:e1005545.

51. Gerc AJ, Diepold A, Trunk K, Porter M, Rickman C, Armitage JP, Stanley-Wall NR, Coulthurst SJ. 2015. Visualization of the Serratia type VI secretion system reveals unprovoked attacks and dynamic assembly. Cell Rep 12:2131-2142.

52. Basler M, Pilhofer M, Henderson GP, Jensen GJ, Mekalanos JJ. 2012. Type VI secretion requires a dynamic contractile phage tail-like structure. Nature 483:182186.

53. Aschtgen MS, Gavioli M, Dessen A, Lloubès R, Cascales E. 2010. The SciZ protein anchors the enteroaggregative Escherichia coli Type VI secretion system to the cell wall. Mol Microbiol 75:886-899.

54. Aschtgen MS, Bernard CS, de Bentzmann S, Lloubès R, Cascales E. 2008. SciN is an outer membrane lipoprotein required for type VI secretion in enteroaggregative Escherichia coli. J Bacteriol 190:7523-7531.

55. Ma LS, Lin JS, Lai EM. 2009. An IcmF family protein, $\operatorname{ImpL}_{M}$, is an integral inner membrane protein interacting with $\operatorname{ImpK}_{\mathrm{L}}$, and its walker a motif is required for type VI secretion system-mediated Hcp secretion in Agrobacterium tumefaciens. $J$ Bacteriol 191:4316-4329.

56. Aschtgen MS, Zoued A, Lloubès R, Journet L, Cascales E. 2012. The C-tail anchored TssL subunit, an essential protein of the enteroaggregative Escherichia coli Sci-1 type VI secretion system, is inserted by YidC. Microbiologyopen 1:71-82.

57. Logger L, Aschtgen MS, Guérin M, Cascales E, Durand E. 2016. Molecular dissection of the interface between the type VI secretion TssM cytoplasmic domain and the TssG baseplate component. J Mol Biol 428:4424-4437.

58. Felisberto-Rodrigues C, Durand E, Aschtgen MS, Blangy S, Ortiz-Lombardia M, Douzi B, Cambillau C, Cascales E. 2011. Towards a structural comprehension of bacterial type VI secretion systems: characterization of the TssJ-TssM complex of an Escherichia coli pathovar. PLoS Pathog 7:e1002386.

59. Rao VA, Shepherd SM, English G, Coulthurst SJ, Hunter WN. 2011. The structure of Serratia marcescens Lip, a membrane-bound component of the type VI secretion system. Acta Crystallogr D Biol Crystallogr. 67:1065-72. doi: 10.1107/S0907444911046300.

60. Robb CS, Assmus M, Nano FE, Boraston AB. 2013. Structure of the T6SS lipoprotein TssJ1 from Pseudomonas aeruginosa. Acta Crystallogr Sect F Struct Biol Cryst Commun. 69:607-10. doi: 10.1107/S1744309113012220.

61. Durand E, Zoued A, Spinelli S, Watson PJ, Aschtgen MS, Journet L, Cambillau C, Cascales E. 2012. Structural characterization and oligomerization of the TssL protein, a component shared by bacterial type VI and type IVb secretion systems. $J$ Biol Chem 287:14157-14168.

62. Robb CS, Nano FE, Boraston AB. 2012. The structure of the conserved type six secretion protein TssL (DotU) from Francisella novicida. J Mol Biol. 419:277-83. doi: 10.1016/j.jmb.2012.04.003.

63. Chang JH, Kim YG. 2015. Crystal structure of the bacterial type VI secretion system component TssL from Vibrio cholerae. J Microbiol. 53:32-7. doi: 10.1007/s12275015-4539-0.

64. Zoued A, Cassaro CJ, Durand E, Douzi B, España AP, Cambillau C, Journet L, Cascales E. 2016. Structure-function analysis of the TssL cytoplasmic domain reveals a new interaction between the type VI secretion baseplate and membrane complexes. $J$ Mol Biol 428:4413-4423. 

E. 2018. Tryptophan-mediated dimerization of the TssL transmembrane anchor is required for type VI secretion system activity. J Mol Biol 430:987-1003.

472

473

474

475

476

477

478

479

480

481

482

483

484

485

486

487

488

489

490

491

492

493

494

495

496

497

498

499

500

501

502

503

504

505

506

507

508

509

510

511

512

513

514

515

516

517

518

66. Zoued A, Durand E, Bebeacua C, Brunet YR, Douzi B, Cambillau C, Cascales E, Journet L. 2013. TssK is a trimeric cytoplasmic protein interacting with components of both phage-like and membrane anchoring complexes of the type VI secretion system. J Biol Chem 288:27031-27041.

67. Nguyen VS, Logger L, Spinelli S, Legrand P, Huyen Pham TT, Nhung Trinh TT, Cherrak Y, Zoued A, Desmyter A, Durand E, Roussel A, Kellenberger C, Cascales E, Cambillau C. 2017. Type VI secretion TssK baseplate protein exhibits structural similarity with phage receptor-binding proteins and evolved to bind the membrane complex. Nat Microbiol 2:17103.

68. Rapisarda C, Cherrak Y, Kooger R, Schmidt V, Pellarin R, Logger L, Cascales E, Pilhofer M, Durand E, Fronzes R. 2019. In situ and high-resolution cryo-EM structure of the type VI secretion membrane complex. EMBO $J$ in press doi:10.15252/embj.2018100886.

69. Yin M, Yan Z, Li X. 2019. Architecture of type VI secretion system membrane core complex. Cell Res 29:251-253.

70. Aschtgen MS, Thomas MS, Cascales E. 2010. Anchoring the type VI secretion system to the peptidoglycan: TssL, TagL, TagP... what else? Virulence 1:535-540.

71. Santin YG, Camy CE, Zoued A, Doan T, Aschtgen MS, Cascales E. 2019. Role and recruitment of the TagL peptidoglycan-binding protein during Type VI secretion system biogenesis. J Bacteriol. pii: JB.00173-19. doi: 10.1128/JB.00173-19.

72. Weber BS, Hennon SW, Wright MS, Scott NE, de Berardinis V, Foster LJ, Ayala JA, Adams MD, Feldman MF. 2016. Genetic dissection of the type VI secretion system in Acinetobacter and identification of a novel peptidoglycan hydrolase, TagX, required for its biogenesis. MBio. 7:e01253-16.

73. Santin YG, Cascales E. 2017. Domestication of a housekeeping transglycosylase for assembly of a Type VI secretion system. EMBO Rep 18:138-149.

74. Russell AB, Wexler AG, Harding BN, Whitney JC, Bohn AJ, Goo YA, Tran BQ, Barry NA, Zheng H, Peterson SB, Chou S, Gonen T, Goodlett DR, Goodman AL, Mougous JD. 2014. A type VI secretion-related pathway in Bacteroidetes mediates interbacterial antagonism. Cell Host Microbe. 16:227-236. doi: 10.1016/j.chom.2014.07.007.

75. Coyne MJ, Roelofs KG, Comstock LE. 2016. Type VI secretion systems of human gut Bacteroidales segregate into three genetic architectures, two of which are contained on mobile genetic elements. BMC Genomics. 17:58. doi: 10.1186/s12864016-2377-z.

76. Nazarov S, Schneider JP, Brackmann M, Goldie KN, Stahlberg H, Basler M. 2018. Cryo-EM reconstruction of Type VI secretion system baseplate and sheath distal end. EMBO J 37:e97103.

77. Cherrak Y, Rapisarda C, Pellarin R, Bouvier G, Bardiaux B, Allain F, Malosse C, Rey M, Chamot-Rooke J, Cascales E, Fronzes R, Durand E. 2018. Biogenesis and structure of a type VI secretion baseplate. Nat Microbiol 3:1404-1416.

78. English G, Byron O, Cianfanelli FR, Prescott AR, Coulthurst SJ. 2014. Biochemical analysis of TssK, a core component of the bacterial type VI secretion system, reveals distinct oligomeric states of TssK and identifies a TssK-TssFG subcomplex. Biochem J 461:291-304.

79. Taylor NM, Prokhorov NS, Guerrero-Ferreira RC, Shneider MM, Browning C, Goldie KN, Stahlberg H, Leiman PG. 2016. Structure of the T4 baseplate and its 
function in triggering sheath contraction. Nature. 533:346-52. doi: 10.1038/nature17971.

80. Büttner CR, Wu Y, Maxwell KL, Davidson AR. 2016. Baseplate assembly of phage $\mathrm{Mu}$ : Defining the conserved core components of contractile-tailed phages and related bacterial systems. Proc Natl Acad Sci USA. 113:10174-9. doi: 10.1073/pnas.1607966113.

81. Kostyuchenko VA, Leiman PG, Chipman PR, Kanamaru S, van Raaij MJ, Arisaka F, Mesyanzhinov VV, Rossmann MG. 2003. Three-dimensional structure of bacteriophage T4 baseplate. Nat Struct Biol. 10:688-93.

82. Planamente S, Salih O, Manoli E, Albesa-Jové D, Freemont PS, Filloux A. 2016. TssA forms a gp6-like ring attached to the type VI secretion sheath. EMBO J. 35:1613-27. doi: 10.15252/embj.201694024.

83. Brunet YR, Espinosa L, Harchouni S, Mignot T, Cascales E. 2013. Imaging type VI secretion-mediated bacterial killing. Cell Rep. 3:36-41. doi: 10.1016/j.celrep.2012.11.027.

84. Ballister ER, Lai AH, Zuckermann RN, Cheng Y, Mougous JD. 2008. In vitro self-assembly of tailorable nanotubes from a simple protein building block. Proc Natl Acad Sci USA 105:3733-3738.

85. Leiman PG, Basler M, Ramagopal UA, Bonanno JB, Sauder JM, Pukatzki S, Burley SK, Almo SC, Mekalanos JJ. 2009. Type VI secretion apparatus and phage tail-associated protein complexes share a common evolutionary origin. Proc Natl Acad Sci USA 106:4154-4159.

86. Brunet YR, Hénin J, Celia H, Cascales E. 2014. Type VI secretion and bacteriophage tail tubes share a common assembly pathway. EMBO Rep 15:315-321.

87. Mougous JD, Cuff ME, Raunser S, Shen A, Zhou M, Gifford CA, Goodman AL, Joachimiak G, Ordoñez CL, Lory S, Walz T, Joachimiak A, Mekalanos JJ. 2006. A virulence locus of Pseudomonas aeruginosa encodes a protein secretion apparatus. Science. 312:1526-30.

88. Douzi B, Spinelli S, Blangy S, Roussel A, Durand E, Brunet YR, Cascales E, Cambillau C. 2014. Crystal structure and self-interaction of the type VI secretion tailtube protein from enteroaggregative Escherichia coli. PLoS One. 9:e86918. doi: 10.1371/journal.pone.0086918.

89. Renault MG, Zamarreno Beas J, Douzi B, Chabalier M, Zoued A, Brunet YR, Cambillau C, Journet L, Cascales E. 2018. The gp27-like hub of VgrG serves as adaptor to promote Hcp tube assembly. J Mol Biol 430:3143-3156.

90. Shneider MM, Buth SA, Ho BT, Basler M, Mekalanos JJ, Leiman PG. 2013. PAAR-repeat proteins sharpen and diversify the type VI secretion system spike. Nature 500:350-353.

91. Leiman PG, Shneider MM. 2012. Contractile tail machines of bacteriophages. $A d v$ Exp Med Biol. 726:93-114. doi: 10.1007/978-1-4614-0980-9_5.

92. Spínola-Amilibia M, Davó-Siguero I, Ruiz FM, Santillana E, Medrano FJ, Romero A. 2016. The structure of VgrG1 from Pseudomonas aeruginosa, the needle tip of the bacterial type VI secretion system. Acta Crystallogr D Struct Biol. 72:2233. doi: $10.1107 / \mathrm{S} 2059798315021142$.

93. Uchida K, Leiman PG, Arisaka F, Kanamaru S. 2014. Structure and properties of the C-terminal $\beta$-helical domain of VgrG protein from Escherichia coli O157. $J$ Biochem. 155:173-82. doi: 10.1093/jb/mvt109.

94. Bönemann G, Pietrosiuk A, Diemand A, Zentgraf H, Mogk A. 2009. Remodelling of VipA/VipB tubules by ClpV-mediated threading is crucial for type VI protein secretion. EMBO J. 28:315-25. doi: 10.1038/emboj.2008.269. 
95. Lossi NS, Dajani R, Freemont P, Filloux A. 2011. Structure-function analysis of HsiF, a gp25-like component of the type VI secretion system, in Pseudomonas aeruginosa. Microbiology. 157:3292-305. doi: 10.1099/mic.0.051987-0.

96. Bröms JE, Ishikawa T, Wai SN, Sjöstedt A. 2013. A functional VipA-VipB interaction is required for the type VI secretion system activity of Vibrio cholerae $\mathrm{O} 1$ strain A1552. BMC Microbiol. 13:96. doi: 10.1186/1471-2180-13-96.

97. Zhang XY, Brunet YR, Logger L, Douzi B, Cambillau C, Journet L, Cascales E. 2013. Dissection of the TssB-TssC interface during type VI secretion sheath complex formation. PLoS One. 8:e81074. doi: 10.1371/journal.pone.0081074.

98. Kube S, Kapitein N, Zimniak T, Herzog F, Mogk A, Wendler P. 2014. Structure of the VipA/B type VI secretion complex suggests a contraction-state-specific recycling mechanism. Cell Rep. 8:20-30. doi: 10.1016/j.celrep.2014.05.034.

99. Kudryashev M, Wang RY, Brackmann M, Scherer S, Maier T, Baker D, DiMaio F, Stahlberg H, Egelman EH, Basler M. 2015. Structure of the type VI secretion system contractile sheath. Cell 160:952-962.

100. Wang J, Brackmann M, Castaño-Díez D, Kudryashev M, Goldie KN, Maier T, Stahlberg H, Basler M. 2017. Cryo-EM structure of the extended type VI secretion system sheath-tube complex. Nat Microbiol 2:1507-1512

101. Brackmann M, Wang J, Basler M. 2018. Type VI secretion system sheath intersubunit interactions modulate its contraction. EMBO Rep. 19:225-233. doi: 10.15252/embr.201744416.

102. Kapitein N, Bönemann G, Pietrosiuk A, Seyffer F, Hausser I, Locker JK, Mogk A. 2013. ClpV recycles VipA/VipB tubules and prevents non-productive tubule formation to ensure efficient type VI protein secretion. Mol Microbiol. 87:1013-28. doi: $10.1111 / \mathrm{mmi} .12147$.

103. Zoued A, Durand E, Brunet YR, Spinelli S, Douzi B, Guzzo M, Flaugnatti N, Legrand P, Journet L, Fronzes R, Mignot T, Cambillau C, Cascales E. 2016. Priming and polymerization of a bacterial contractile tail structure. Nature 531:59-63.

104. Vettiger A, Winter J, Lin L, Basler M. 2017. The type VI secretion system sheath assembles at the end distal from the membrane anchor. Nat Commun 8:16088.

105. Zoued A, Durand E, Santin YG, Journet L, Roussel A, Cambillau C, Cascales E. 2017. TssA: The cap protein of the Type VI secretion system tail. Bioessays 39:10.

106. Santin YG, Doan T, Lebrun R, Espinosa L, Journet L, Cascales E. 2018. In vivo TssA proximity labelling during type VI secretion biogenesis reveals TagA as a protein that stops and holds the sheath. Nat Microbiol 3:1304-1313.

107. Dix SR, Owen HJ, Sun R, Ahmad A, Shastri S, Spiewak HL, Mosby DJ, Harris MJ, Batters SL, Brooker TA, Tzokov SB, Sedelnikova SE, Baker PJ, Bullough PA, Rice DW, Thomas MS. 2018. Structural insights into the function of type VI secretion system TssA subunits. Nat Commun 9:4765.

108. Pietrosiuk A, Lenherr ED, Falk S, Bönemann G, Kopp J, Zentgraf H, Sinning I, Mogk A. 2011. Molecular basis for the unique role of the AAA+ chaperone ClpV in type VI protein secretion. $J$ Biol Chem. 286:30010-21. doi: 10.1074/jbc.M111.253377.

109. Douzi B, Brunet YR, Spinelli S, Lensi V, Legrand P, Blangy S, Kumar A, Journet L, Cascales E, Cambillau C. 2016. Structure and specificity of the Type VI secretion system ClpV-TssC interaction in enteroaggregative Escherichia coli. Sci Rep. 6:34405. doi: 10.1038/srep34405.

110. Unterweger D, Kostiuk B, Pukatzki S. 2017. Adaptor proteins of type VI secretion system effectors. Trends Microbiol. 25:8-10. doi: 10.1016/j.tim.2016.10.003. 
111. Ma J, Pan Z, Huang J, Sun M, Lu C, Yao H. 2017. The Hcp proteins fused with diverse extended-toxin domains represent a novel pattern of antibacterial effectors in type VI secretion systems. Virulence. 8:1189-1202. doi: 10.1080/21505594.2017.1279374.

112. Brooks TM, Unterweger D, Bachmann V, Kostiuk B, Pukatzki S. 2013. Lytic activity of the Vibrio cholerae type VI secretion toxin VgrG-3 is inhibited by the antitoxin TsaB. J Biol Chem. 288:7618-25. doi: 10.1074/jbc.M112.436725.

113. Toesca IJ, French CT, Miller JF. 2014. The Type VI secretion system spike protein VgrG5 mediates membrane fusion during intercellular spread by pseudomallei group Burkholderia species. Infect Immun. 82:1436-44. doi: 10.1128/IAI.01367-13.

114. Silverman JM, Agnello DM, Zheng H, Andrews BT, Li M, Catalano CE, Gonen T, Mougous JD. 2013. Haemolysin coregulated protein is an exported receptor and chaperone of type VI secretion substrates. Mol Cell. 51:584-93. doi: 10.1016/j.molcel.2013.07.025.

115. Whitney JC, Beck CM, Goo YA, Russell AB, Harding BN, De Leon JA, Cunningham DA, Tran BQ, Low DA, Goodlett DR, Hayes CS, Mougous JD. 2014. Genetically distinct pathways guide effector export through the type VI secretion system. Mol Microbiol. 92:529-42. doi: 10.1111/mmi.12571.

116. Unterweger D, Miyata ST, Bachmann V, Brooks TM, Mullins T, Kostiuk B, Provenzano D, Pukatzki S. 2014. The Vibrio cholerae type VI secretion system employs diverse effector modules for intraspecific competition. Nat Commun. 5:3549. doi: $10.1038 /$ ncomms4549.

117. Liang X, Moore R, Wilton M, Wong MJ, Lam L, Dong TG. 2015. Identification of divergent type VI secretion effectors using a conserved chaperone domain. Proc Natl Acad Sci USA. 112:9106-11. doi: 10.1073/pnas.1505317112.

118. Unterweger D, Kostiuk B, Ötjengerdes R, Wilton A, Diaz-Satizabal L, Pukatzki S. 2015. Chimeric adaptor proteins translocate diverse type VI secretion system effectors in Vibrio cholerae. EMBO J. 34:2198-210. doi: 10.15252/embj.201591163.

119. Alcoforado Diniz J, Coulthurst SJ. 2015. Intraspecies competition in Serratia marcescens is mediated by type VI-secreted Rhs effectors and a conserved effectorassociated accessory protein. J Bacteriol. 197:2350-60. doi: 10.1128/JB.00199-15.

120. Flaugnatti N, Le TT, Canaan S, Aschtgen MS, Nguyen VS, Blangy S, Kellenberger C, Roussel A, Cambillau C, Cascales E, Journet L. 2016. A phospholipase A1 antibacterial type VI secretion effector interacts directly with the Cterminal domain of the VgrG spike protein for delivery. Mol Microbiol 99:1099-1118.

121. Bondage DD, Lin JS, Ma LS, Kuo CH, Lai EM. 2016. VgrG C terminus confers the type VI effector transport specificity and is required for binding with PAAR and adaptor-effector complex. Proc Natl Acad Sci USA. 113:E3931-40. doi: 10.1073/pnas.1600428113.

122. Cianfanelli FR, Alcoforado Diniz J, Guo M, De Cesare V, Trost M, Coulthurst SJ. 2016. VgrG and PAAR proteins define distinct versions of a functional type VI secretion system. PLoS Pathog. 12:e1005735. doi: 10.1371/journal.ppat.1005735.

123. Ma J, Sun M, Dong W, Pan Z, Lu C, Yao H. 2017. PAAR-Rhs proteins harbor various C-terminal toxins to diversify the antibacterial pathways of type VI secretion systems. Environ Microbiol. 19:345-360. doi: 10.1111/1462-2920.13621.

124. Quentin D, Ahmad S, Shanthamoorthy P, Mougous JD, Whitney JC, Raunser S. 2018. Mechanism of loading and translocation of type VI secretion system effector Tse6. Nat Microbiol. 3:1142-1152. doi: 10.1038/s41564-018-0238-z. 
125. Burkinshaw BJ, Liang X, Wong M, Le ANH, Lam L, Dong TG. 2018. A type VI secretion system effector delivery mechanism dependent on PAAR and a chaperoneco-chaperone complex. Nat Microbiol. 3:632-640. doi: 10.1038/s41564-018-0144-4. carte" delivery systems for bacterial type VI effectors. J Biol Chem. 289:17872-84. doi: 10.1074/jbc.M114.563429. 


\section{LEGEND TO FIGURES}

673

674 FIGURE 1 Schematic representation of the Type VI secretion system. The different subunits 675 are labeled, as well as the different subcomplexes. IM, inner membrane; OM, outer 676 membrane.

677

678 FIGURE 2 Assembly and mechanism of firing of the Type VI secretion system. T6SS 679 biogenesis starts with the positioning and assembly of the membrane complex, and the 680 assembly of the baseplate (1). The recruitment and docking of the baseplate on the membrane 681 complex (2) initiates the TssA-mediated polymerization of the tail tube/sheath tubular 682 structure $(3,4,5)$, which is stopped when hitting the opposite membrane by the TagA stopper 683 (5). Sheath contraction propels the tube/spike needle into the target (6). The ClpV ATPase is 684 recruited to the contracted sheath to recycle sheath subunits (6). Needle components, and 685 effectors associated to them, are delivered inside the target (7).

686

687 FIGURE 3 Schematic representation of the mechanisms of effector loading. Effectors are 688 depicted as red circles. Specialized effectors are chimeric needle proteins with extensions 689 encoding the effector. Cargo effectors are independent proteins that associate to needle 690 components (Hcp, VgrG, PAAR). Binding of cargo effectors to needle components could be 691 direct, or mediated by adaptor modules that are independent proteins (adaptors) or extensions 692 of VgrG and PAAR (internal adaptors). 


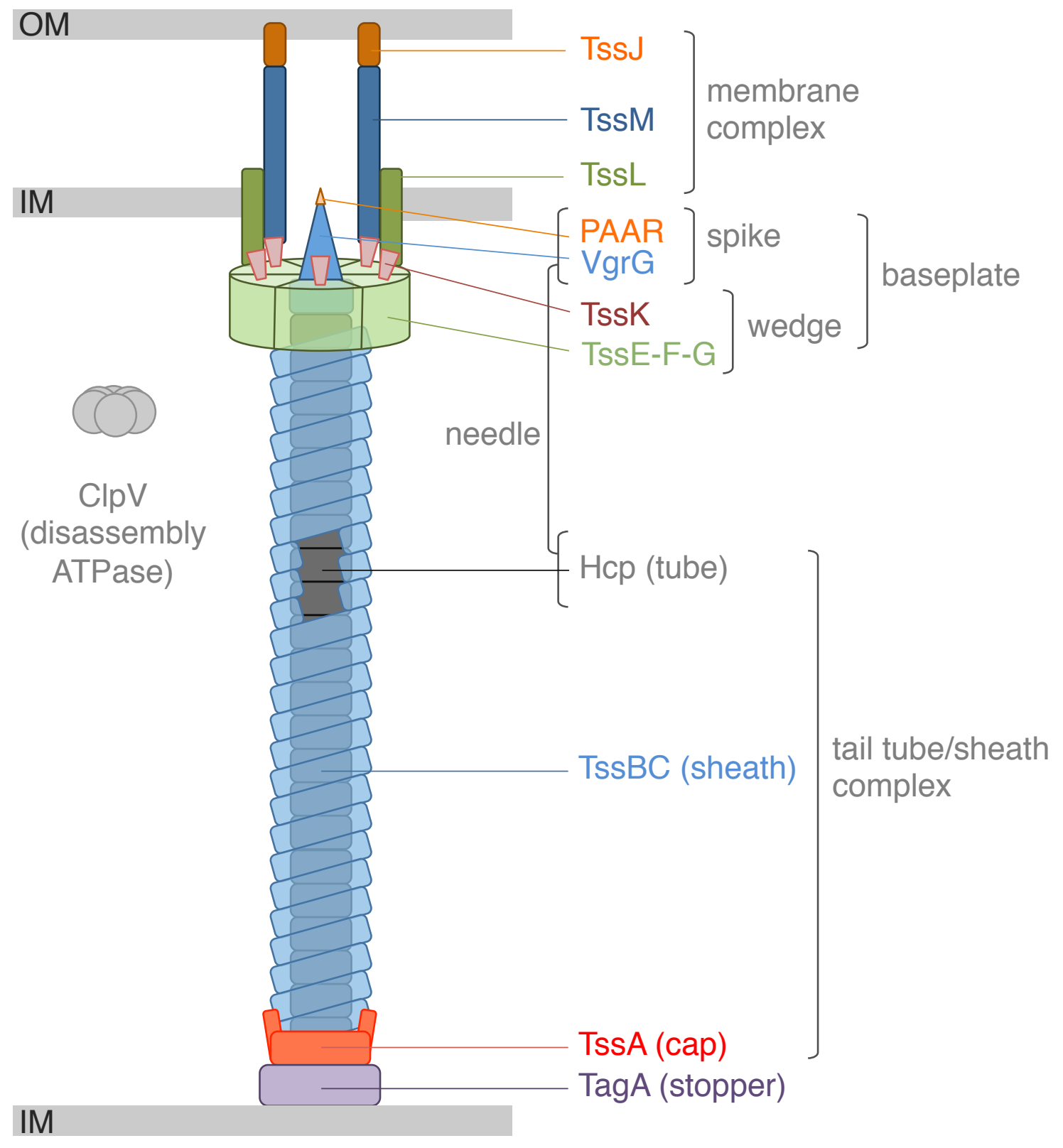




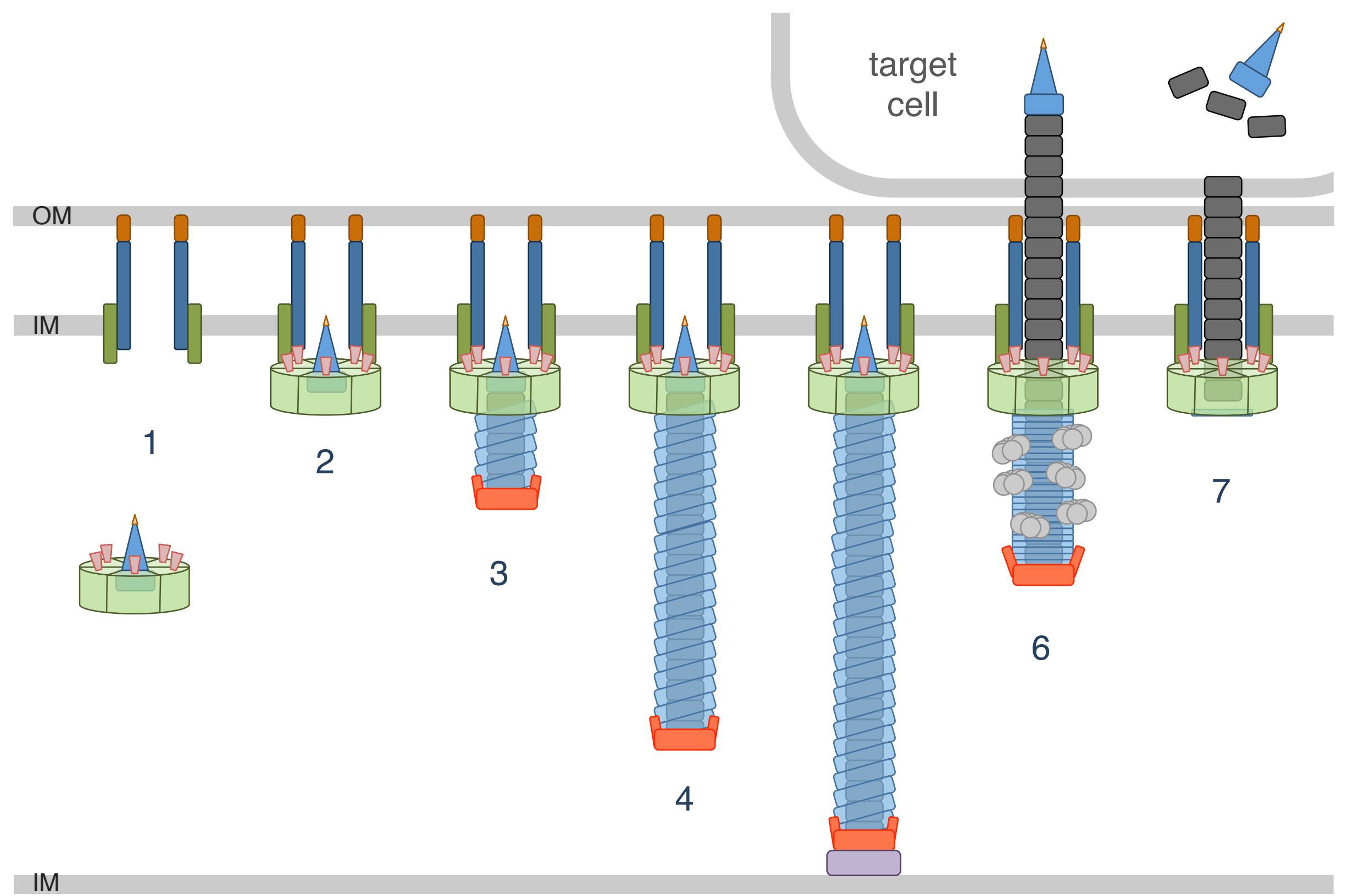


$\operatorname{PAAR} \triangle$

effector

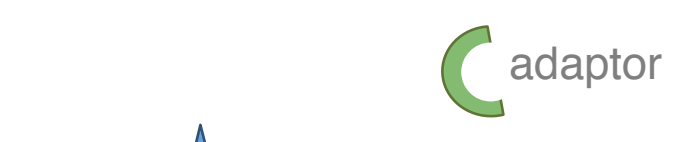

$\operatorname{VgrG~}$

Hсp

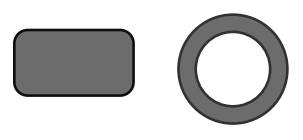

needle

components
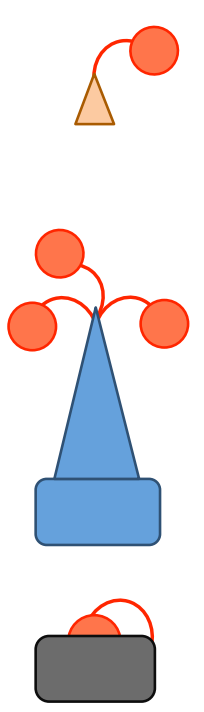

specialized effectors
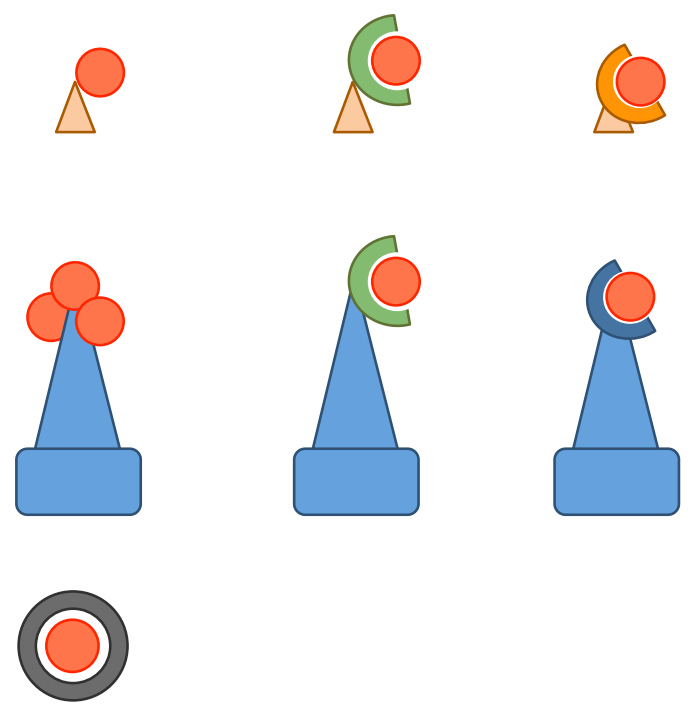

$$
\begin{array}{r}
\text { direct binding adaptors internal } \\
\text { adaptors }
\end{array}
$$

cargo

effectors 